\title{
CLINICAL EVALUATION OF THYROID SWELLINGS
}

\author{
Vikrant Kumar1, Vaibhav Kuchhal2, Tushar Sharma \\ 13 ${ }^{\text {rd }}$ Year Post Graduate, Department of Otorhinolaryngology and Head and Neck Surgery, Government Medical College and Hospital, \\ Haldwani. \\ ${ }^{2}$ Professor and HOD, Department of Otorhinolaryngology and Head and Neck Surgery, Government Medical College and Hospital, \\ Haldwani. \\ ${ }^{32} 2^{\text {nd }}$ Year Post Graduate, Department of Otorhinolaryngology and Head and Neck Surgery, Government Medical College and Hospital, \\ Haldwani.
}

\section{ABSTRACT}

\section{BACKGROUND}

Thyroid nodule is the most common entity and presentation of underlying thyroid pathology. Term goitre is generalized enlargement of thyroid gland. The management of thyroid swelling depends on clinical examination, battery of tests to reach correct diagnosis.

\section{METHODS}

This is prospective study of clinical evaluation of thyroid swellings done on 100 patients presented with palpable thyroid swellings in Department of Otorhinolaryngology and Head and Neck Surgery, Government Medical College and Hospital, Haldwani, Nainital, Uttarakhand. The time period of study was from November 2013 to November 2015.

\section{RESULTS}

Thyroid swellings is more common in females (M:F ratio 1:5.66). Majority of the patients are in the age group of 31-40 years. Swelling in the anterior neck was the commonest mode of presentation. In majority of the patients, duration of swelling prior to presentation was between 6 months and 3 years.

\section{KEYWORDS}

Thyroid Nodule, Multinodular Goitre, Diffuse Goitre.

HOW TO CITE THIS ARTICLE: Kumar V, Kuchhal V, Sharma T. Clinical evaluation of thyroid swellings. J. Evolution Med. Dent. Sci. 2016;5(42):2591-2596, DOI: 10.14260/jemds/2016/606

\section{INTRODUCTION}

Thyroid gland is unique among endocrine organs as it is the largest endocrine gland in the body and the first to develop in foetal life. Even after 100 years, thyroid gland has been the subject of intense research and considerable attention due to the vast array of developmental, inflammatory, hyper plastic and neoplastic disorders which are exceedingly common in clinical practice.[1] Most common clinical finding in the thyroid gland is thyroid nodule which is defined as any abnormal growth of thyroid cells into a lump within thyroid. Benign nodules can be caused by adenomas, colloid nodules, cysts, infectious nodules, lymphocytic or granulomatous nodules, hyper plastic nodules, thyroiditis, and congenital anomalies.

\section{Malignant Nodules are classified as}

1. Differentiated: a) Papillary adenocarcinoma, b) Follicular adenocarcinoma.

2. Medullary carcinoma.

3. Undifferentiated: a) Small cell, b) Giant cell, c) Carcinosarcoma

Financial or Other, Competing Interest: None.

Submission 11-03-2016, Peer Review 14-04-2016,

Acceptance 18-04-2016, Published 25-05-2016.

Corresponding Author:

Dr. Vikrant Kumar,

Room No. 62,

New SR Hostel,

Government Medical College,

Haldwani, Nainital.

Uttarakhand.

E-mail:dr.vikrantroy@gmail.com

DOI: $10.14260 /$ jemds/2016/606
4. Miscellaneous: a) Lymphoma, sarcoma, b) Squamous cell carcinoma, c) Fibrosarcoma, d) Mucoepithelial carcinoma, e) Metastatic tumours.

These nodules have a reported prevalence of $4-7 \%$ of adult population.[2] The incidence of clinically apparent thyroid nodules in general population is $4 \%-5 \%{ }^{[3]}$ Moreover $20-48 \%$ of patients with single palpable thyroid nodule (Significant if size $>1 \mathrm{~cm}$ ) are found to have additional nodules when investigated by Ultrasound. ${ }^{[3]}$ We are thus facing an epidemic of thyroid nodules. Local compressive symptoms or thyroid hyperfunction is primarily the need to exclude the presence of thyroid malignant lesions, which account for $5 \%$ of all thyroid nodules.

These thyroid cancers account for $0.4 \%$ of all cancer deaths with mortality rate of 8 in 1.5 million people per year.[1] Hence, different diagnostic modalities are used to evaluate and diagnose efficiently thyroid nodules. These include Clinical Examinations, Thyroid Function Tests (TFT), Scintiscan, Ultrasonography (USG), Fine Needle Aspiration Cytology (FNAC), and Histopathological examination. Clinical examination although very accurate in most cases, it is inadequate in some areas, especially in staging of thyroid malignancies and in detecting the multinodularity of the gland. Most importantly the application of ultrasound in the preoperative evaluation has enhanced the armamentarium of the head and neck surgeons. Rapid evolution in sonographic technology has made ultrasound an important adjunct to the practice of head and neck surgery.

Ultrasound of the neck is extremely sensitive in detecting thyroid and cervical lymph node pathology and is felt to be the most complete and cost-effective imaging method for the 
evaluation of the thyroid gland. Diseases of thyroid gland, especially multinodular goitre due to deficiency of iodine is prevalent in India. India has the world's biggest goitre belt in the Sub-Himalayan region with nearly 55 million cases are estimated to be suffering from endemic goitre. Currently, no less than 140 million people are estimated to be living in goitre endemic regions of the country. ${ }^{1}$ There are certain features that will help to identify benign from malignant lesions. FNAC and USG are used in association with clinical features, but there are drawbacks of each technique and the final answer to the problem is still elusive.

The present study is undertaken to evaluate usefulness of clinical features, FNAC and USG in managing thyroid nodule. ${ }^{1}$

Thyroid gland developed from the median anlage and two lateral analge. The median analge begins as an endodermal thickning (Bud) from the floor of the pharynx between the first and second brachial arches at base of tongue which constitute foramen caecum. Elongation of this bud forms a tubular outgrowth known as the thyroglossal duct continues inferiorly or caudally into the neck until the duct lies in a plane anterior to the developing tracheobronchial bud. As the development progresses, a bilobed organ connected by, a midline isthmus is eventually formed. Certain abnormalities connected with thyroid development include arrested growth, accessory tissues and cystic development of the thyroglossal duct.

In case of arrested development of the thyroid, the gland may not migrate beyond the point of origin in the floor of the pharynx. In this case, it may present as a lingual thyroid. Lingual thyroid may coexist with other thyroid tissues varying from minimal tissue nodules to a hemi-thyroid or normal thyroid. Even when there is normal development of the thyroid glands, there may be accessory thyroid tissue in the region of the neck at any point along the original track of the thyroid gland or beyond it in the mediastinal space or on rare occasion in the tracheal wall.

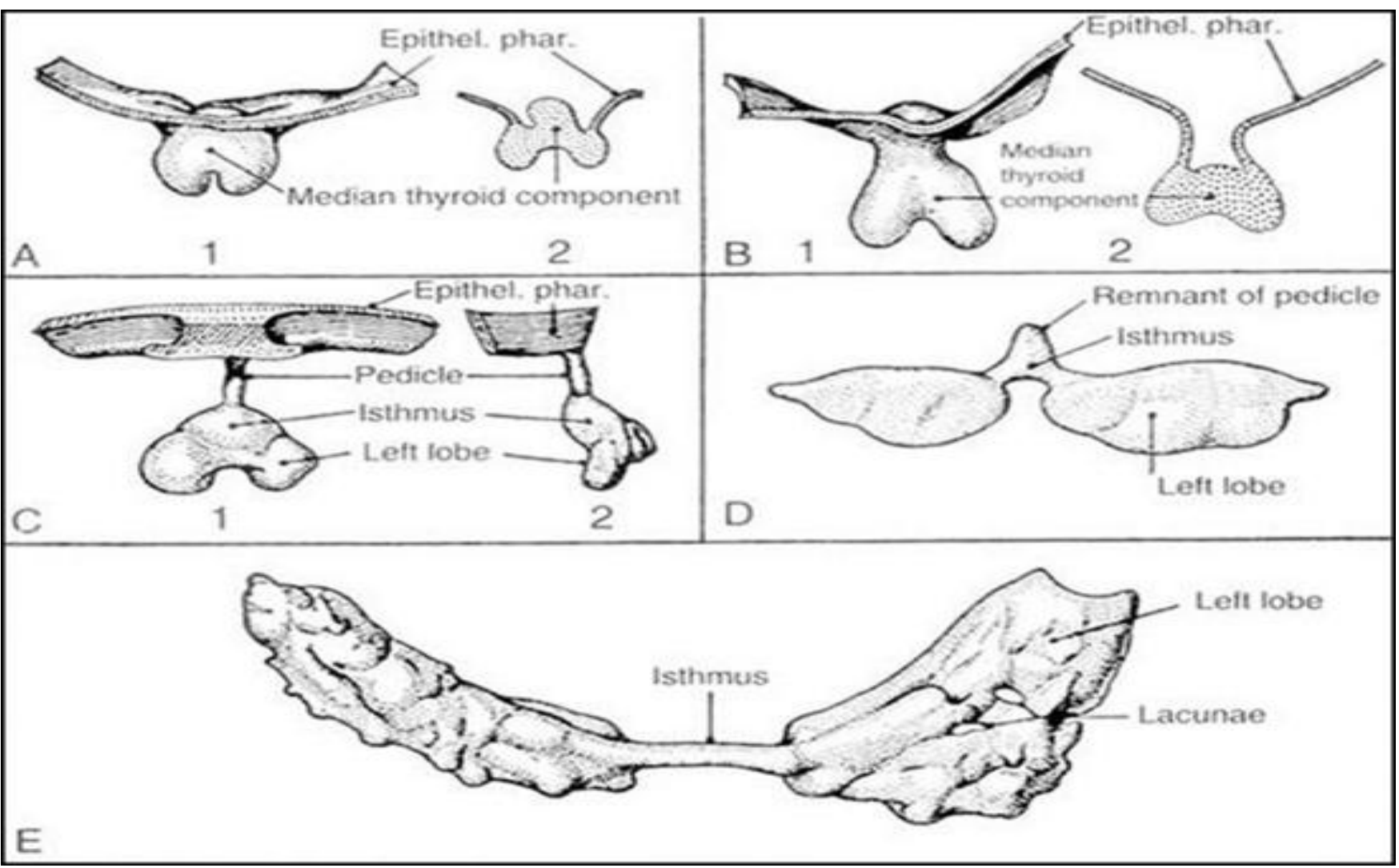

Fig. 1: Development of Thyroid Gland.4

Thyroid gland is shield shaped, although its form varies considerably, sometimes being more $\mathrm{H}$ or more $\mathrm{U}$ shaped. Each of the elongated lateral lobes consists of inferior and superior pole. In the normal subject, the isthmus overlies the third tracheal ring cartilage. The gland is brownish red and highly vascular and lies approximately at the level of the fifth cervical to the first thoracic vertebra. The gland is ensheathed by the pretracheal layer of deep cervical fascia. Its weight is usually about 25 grams but varies slightly, heavier in females and enlarging during menstruation and pregnancy. The lobes of the thyroid are approximately conical; their ascending apices diverging laterally to the oblique lines of the thyroid cartilages, their bases are level with the fourth and fifth cartilages.

Each lobe is about $4 \mathrm{~cm}$ long, its greatest transverse and anteroposterior extent being about $2-3 \mathrm{~cm}$ and $2 \mathrm{~cm}$ respectively. The posteromedial aspect of the lobe is attached to the side of the cricoid cartilage by a lateral thyroid ligament. The lateral superficial surface is convex and is covered by the sternothyroid muscle. The medial surface is adapted to the larynx and trachea and on its superior pole are the inferior pharyngeal constrictor and the posterior part of cricothyroid muscles. The external laryngeal nerve is medial to this part of the gland. Below the trachea and posterior to it is the recurrent laryngeal nerve and oesophagus as the medial relations. The posterolateral surface is next to the carotid sheath overlapping the common carotid artery. The parathyroid glands are related to the rounded posterior border.

The isthmus connects the lobe's inferior aspects. It measures $1.25 \mathrm{~cm}$ transversely and vertically and is usually anterior to the second and third tracheal cartilages. The 
superior thyroid arteries anastomose along its upper border. At the lower border, the inferior thyroid veins leave the gland. Small-detached masses of thyroid tissue may occur above the lobes or isthmus as accessory thyroid glands.

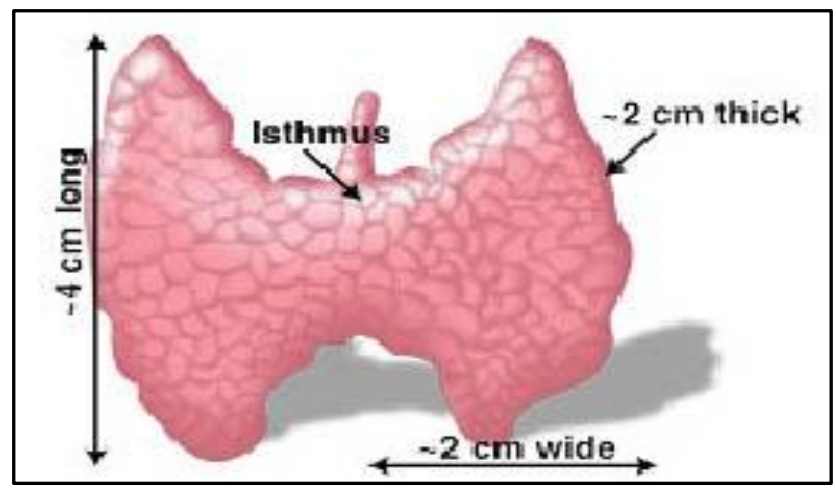

Fig. 2: Anatomy of Thyroid

The thyroid gland receives a dual blood supply from the superior and inferior thyroid arteries. Superior thyroid arteries are the first branch of the external carotid artery. In a small percentage of cases, it may arise from the common carotid artery just before its bifurcation into the internal and external branches. Inferior thyroid artery arises from the thyrocervical trunk, a branch of the first part of the subclavian artery at the level of the first rib. It ascends vertically for a short distance before turning medially, forming an arching loop and entering the tracheo-oesophageal groove. Although two pairs of arteries supply the thyroid, three pairs of veins provide the venous drainage.
The superior thyroid vein parallels the course of the superior thyroid artery on the anterior surface of the thyroid, as it ascends to become a tributary of the internal jugular vein. A middle thyroid vein usually the shortest of the three pairs has a direct lateral course from the surface of the thyroid to the internal jugular vein. The inferior thyroid vein lies on the anterior surface of the thyroid gland compared with the posterior position of the corresponding artery. It has an almost vertical downward course before entering the brachiocephalic vein. ${ }^{5}$ Within the gland lymphatic channels occur immediately beneath the capsule and communicate between lobes through the isthmus. Lymph from the upper part of the gland reaches the deep cervical lymph nodes, either directly or through the pre-laryngeal nodes.

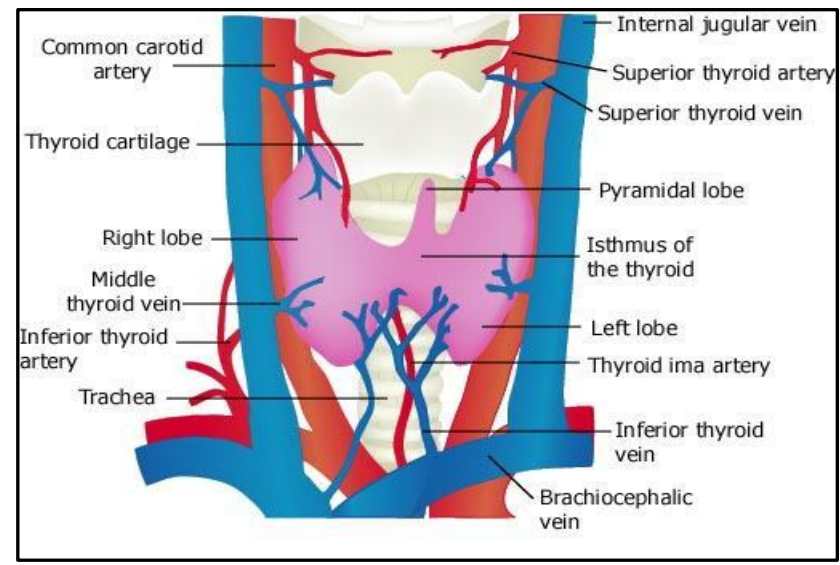

Fig. 3: Blood Supply of Thyroid
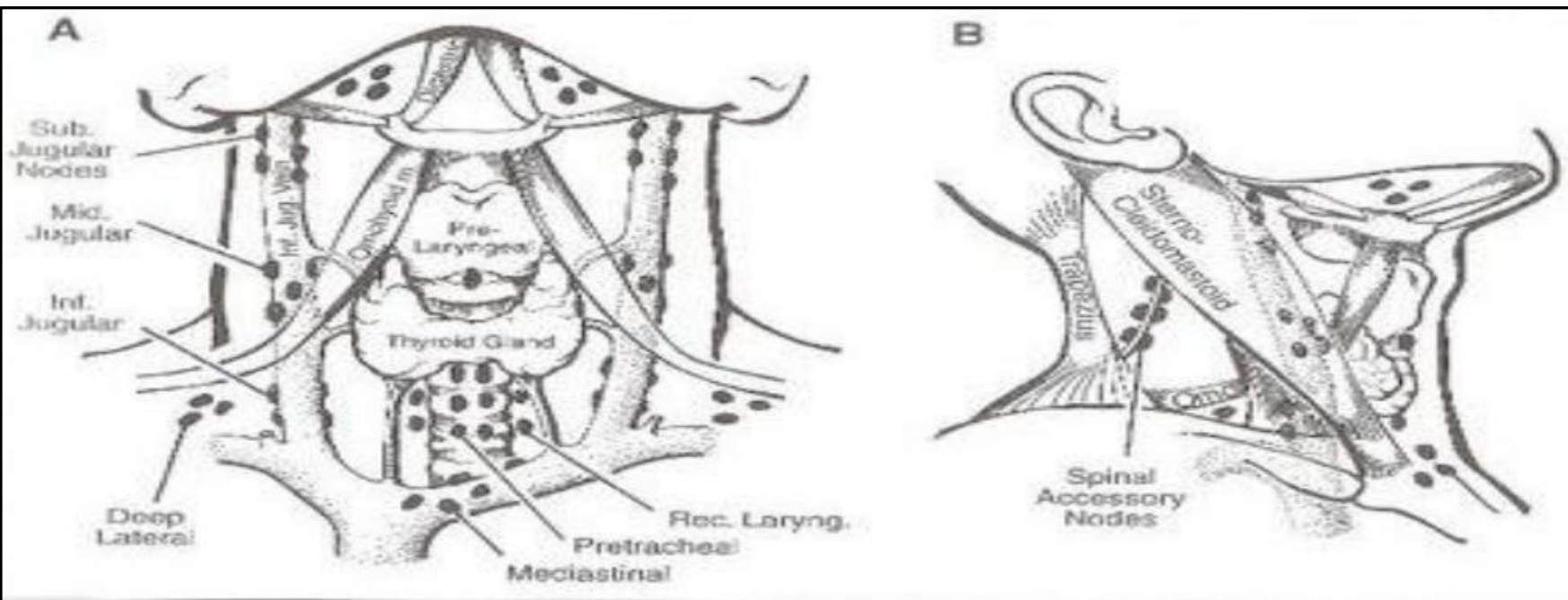

Fig. 4: Lymphatic Drainage of Thyroid Gland

Recurrent laryngeal nerve: Innervates the intrinsic musculature and provide sensory innervation to the glottic larynx. The RLN arises from the vagus at the level of the subclavian artery on the right and at the level of aortic arch on the left. The nerves then turn superomedially to run towards the tracheo-oesophageal groove, giving off oesophageal and tracheal branches. The RLN ascends in close relation with the trachea and oesophagus, but not necessarily in the true TE groove. ${ }^{6}$ Weisberg et al stated that the right RLN is at a higher risk for stretch injuries during cervical spine surgeries, because of its lateral position relative to TE groove. Typically, the nerves may pass superficial or deep or between branches of the inferior thyroid artery. The position of nerve can be influenced by the formation of the suspensory ligament of the thyroid gland. It is the pretracheal fascia that covers the thyroid gland, condenses and attaches the thyroid to the upper two to three tracheal rings. RLN often passes through this layer on its way to enter the larynx. RLN may divide extralaryngeally in $35-80 \%$ of anatomic dissection. 


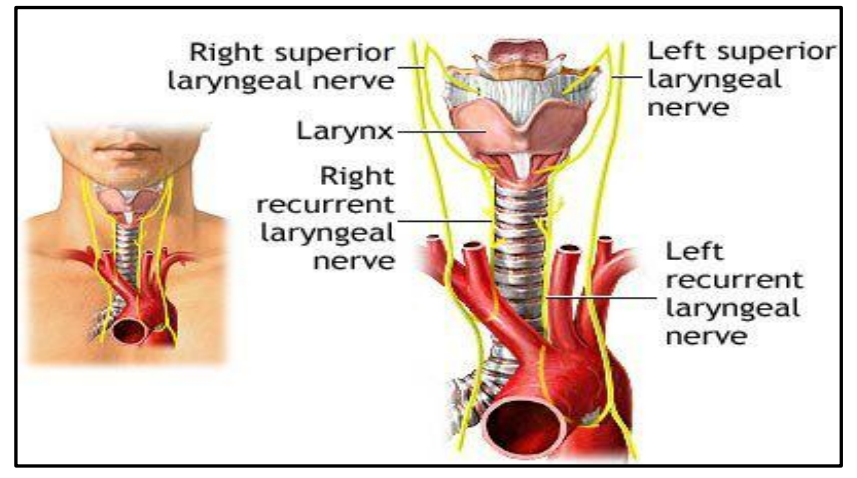

Fig. 5: Nerve Supply of Thyroid Gland

The gland is composed of lobules containing clusters of follicles that are 30 to 500 um in diameter. These follicles are the structural units of the gland and each is composed of a droplet of colloid that contains stored thyroglobulin (Tg). A single layer of follicular epithelial cells surrounds this. Groups of 20-40 follicles bound together by connective tissue and supplied by an arterial twig constitute a thyroid lobule. To release the hormone, the follicular cells reincorporate the stored colloid by endocytosis and pinocytosis. They hydrolyse the Tg and secreted thyroxine (T4) with smaller quantities of triiodothyronine (T3). ${ }^{7}$ The remaining fragments of hydrolysis are used for resynthesis of $\mathrm{Tg}$. C cells or parafollicular are dispersed with the follicles, especially in the posterior lateral parts of the lateral lobe. They make up about $0.1 \%$ of the epithelial mass.
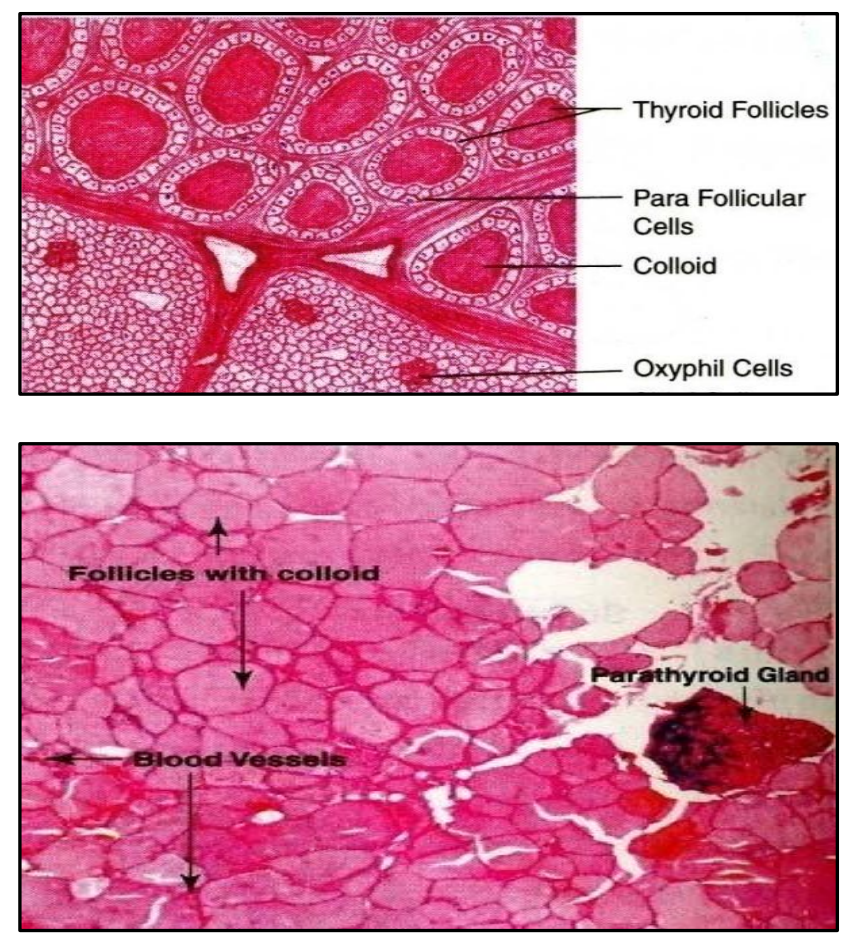

Fig. 6: Ultrastructure of Thyroid Gland

\section{MATERIALS AND METHODS}

It includes prospective study of patients presenting with palpable thyroid swellings in ENT OPD at Dr. Sushila Tiwari Govt. Hospital, Haldwani, Nainital. Patients presenting with thyroid swellings is included in the study during study period of November 2013 to November 2015. Patients who refused and not giving the consents and swellings other than thyroid were excluded from the study group.

\section{OBSERVATIONS AND RESULT}

\begin{tabular}{|c|c|c|c|}
\hline Age & Male (15) & Female (85) & Total (100) \\
\hline $10-20$ & 1 & 7 & 8 \\
\hline $21-30$ & 3 & 22 & 25 \\
\hline $31-40$ & 5 & 35 & 40 \\
\hline $41-50$ & 2 & 14 & 16 \\
\hline $51-60$ & 2 & 6 & 8 \\
\hline $61-70$ & 2 & 1 & 3 \\
\hline \multicolumn{2}{|c|}{ Table 1: Age and Sex Distribution of Patients } \\
\hline
\end{tabular}

The age of patient ranges from $10 \mathrm{yrs}$. to $70 \mathrm{yrs}$. The commonest age group with thyroid pathology is between 31$40 \mathrm{yrs}$. and mean age group is 34.5 years. Male-to-female ratio is $1: 5.66$.

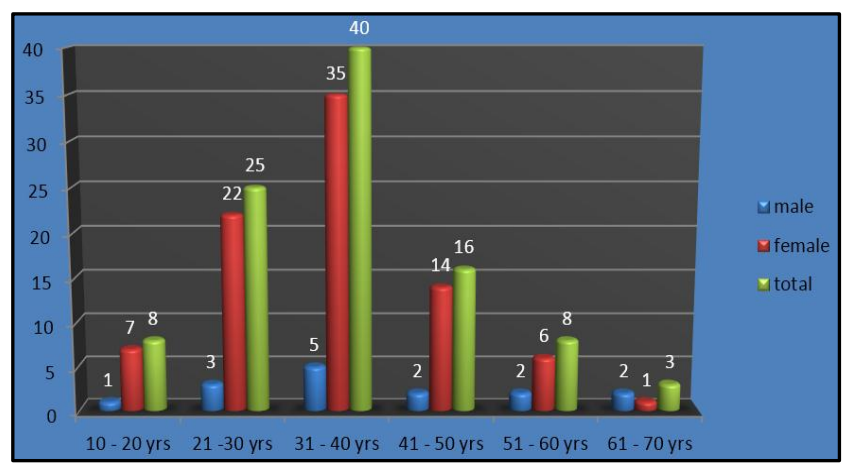

Fig. 1a: Age and Sex Distribution

\begin{tabular}{|c|c|c|}
\hline Sl. No. & Duration of Complaints & No. of Patients \\
\hline 1 & Less than six months & 20 \\
\hline 2 & Six months to three years & 69 \\
\hline 3 & More than three years & 11 \\
\hline \multicolumn{3}{|c|}{ Table 2: Duration of Complaints } \\
\hline
\end{tabular}

The duration of complaints ranges from one month to 20 years. Majority of patients presented between 6 months to 3 years.

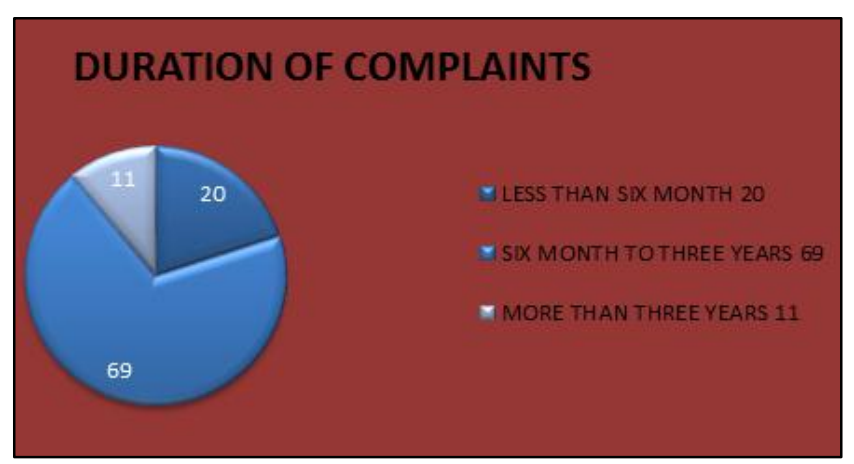

Fig. 2a: Duration of Complaints

\begin{tabular}{|c|c|c|c|}
\hline $\begin{array}{c}\text { Sl. } \\
\text { No. }\end{array}$ & $\begin{array}{c}\text { Clinical } \\
\text { Presentation }\end{array}$ & $\begin{array}{c}\text { No. of } \\
\text { Patients }\end{array}$ & Percentage \\
\hline 1 & Multinodular Goitre & 22 & $22 \%$ \\
\hline 2 & $\begin{array}{c}\text { Diffuse } \\
\text { Enlargement }\end{array}$ & 20 & $20 \%$ \\
\hline 3 & Solitary Nodule & 58 & $58 \%$ \\
\hline \multicolumn{3}{|c|}{ Table 3: Clinical Diagnosis } \\
\hline
\end{tabular}


On clinical examination out of 100 thyroid swellings 58 are solitary nodular goitre, 22 thyroid swellings diagnosed as multinodular goitre and 20 are diffuse enlargement.

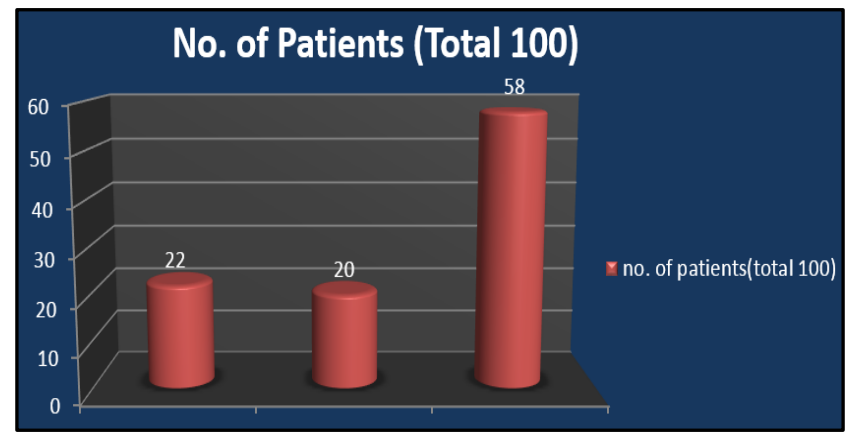

Fig. 3a: Clinical Diagnosis

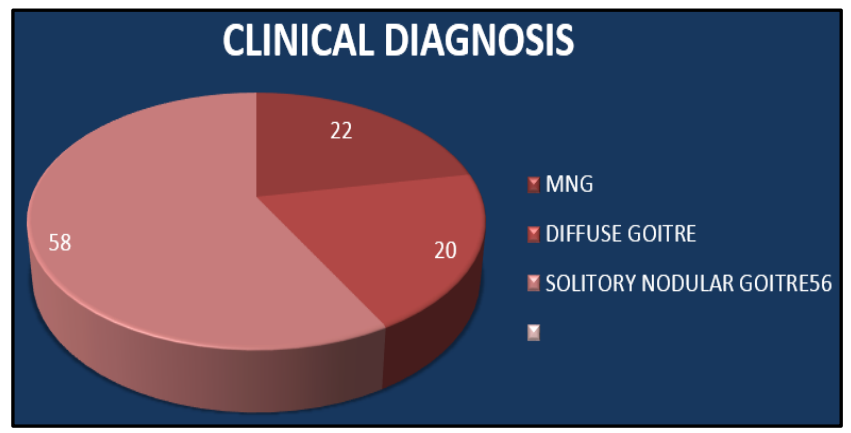

Fig. 3b: Clinical Diagnosis

\begin{tabular}{|c|c|c|c|}
\hline $\begin{array}{c}\text { Sl. } \\
\text { No. }\end{array}$ & Thyroid Status & No. of Patient & Percentage \\
\hline 1 & Hypothyroid & 38 & 38 \\
\hline 2 & Euthyroid & 50 & 50 \\
\hline 3 & Hyperthyroid & 12 & 12 \\
\hline \multicolumn{4}{|c|}{ Table 4: Thyroid Status at Presentation } \\
\hline
\end{tabular}

Out of hundred thirty eight patients are hypothyroid, twelve patients are hyperthyroid and fifty patients are euthyroid status at the time of presentation.

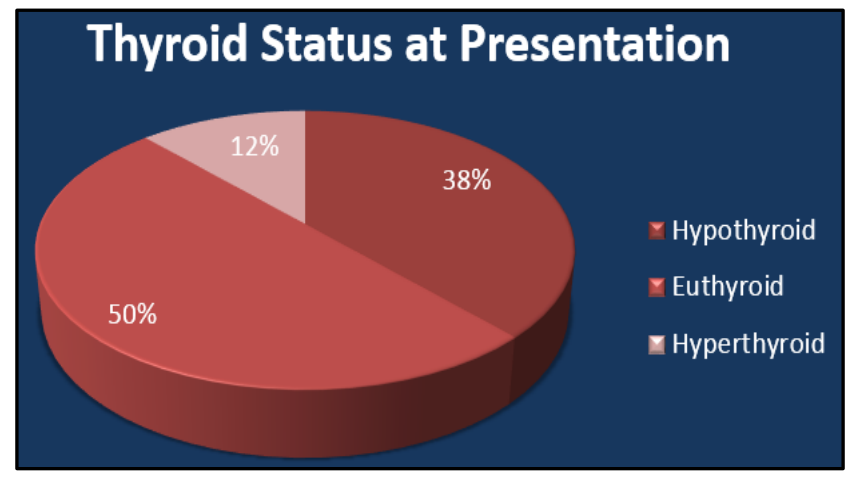

Fig. 4: Thyroid Status at Presentation

\begin{tabular}{|c|c|c|}
\hline $\begin{array}{c}\text { Sl. } \\
\text { No. }\end{array}$ & Presenting Complaints & No. of Patients \\
\hline 1 & Swelling in front of neck & 100 \\
\hline 2 & Pain in swelling & 15 \\
\hline 3 & Difficulty in swallowing & 12 \\
\hline 4 & Difficulty in breathing & 5 \\
\hline 5 & Symptoms of hypothyroidism & 18 \\
\hline 6 & Symptoms of hyperthyroidism & 10 \\
\hline 7 & Lymph node involvements & 8 \\
\hline \multicolumn{3}{|c|}{ Table 5: Presenting Complaints } \\
\hline
\end{tabular}

All the hundred patients that are included in study presented with palpable thyroid swellings (Solitary nodule, MNG or diffuse swelling). Fifteen patients presented with pain in and around thyroid swelling, mild and diffuse pain nonradiating. Twelve patients have difficulty in swallowing, whereas five patients complained of difficulty in breathing on strenuous work.

Lymph node palpable in eight patients, among them seven diagnosed as papillary carcinoma thyroid $(\mathrm{M}=3, \mathrm{~F}=4)$ and one patient diagnosed as medullary carcinoma having palpable lymph node swellings. The symptoms suggestive of hyperthyroidism was seen in eighteen patients, but after evaluating thyroid profile thirty eight patients diagnosed as hypothyroid.

The symptoms suggestive of hyperthyroidism seen in is ten patients, but after evaluating thyroid profile fourteen patients diagnosed as hyperthyroidism.

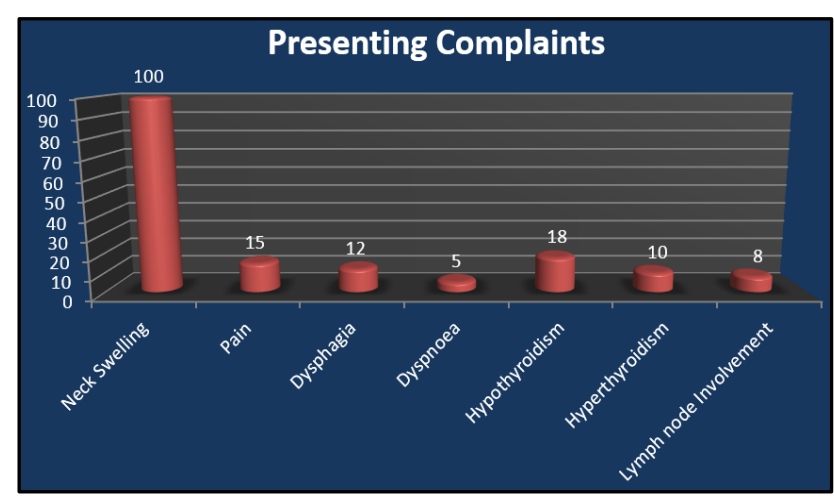

Fig. 5: Presenting Complaints

\section{DISCUSSION}

In the present study, age of the patient ranged from 11-70 years with a median age of 35.5 years. Age distribution of the present study is comparable to Jose $\mathrm{R} \mathrm{J}$ et al (2002). ${ }^{8}$ Tabaqchali et al (2000). ${ }^{2}$ in their study found thyroid nodule in age ranging from 8.5 years to 85 years and the median age is 48 years. In a prospective study conducted by Sekhri et al (2001). ${ }^{9}$ found that thyroid swelling ranged between 9 years of age to 70 years with mean age of 33.9 years. Jose R S et al (2002). ${ }^{8}$ in their prospective study concluded median age of thyroid swelling was 35.5 years and the thyroid nodule present between age group of 17 years to 65 years.

The number of males in the present study was 15 (15\%) and the females were 85 (85\%) with a male-to-female ratio of 1:6. Sex distribution was similar when compared to Sekhri T et al (2001). ${ }^{9}$ Sekhri T et al (2001). ${ }^{9}$ in a prospective study group of total 300 patients with thyroid nodule, 256 patients were females and 44 were males and male-female ratio was 1:6.88.10 In a prospective study conducted by Afroz et al in 2002 on 172 patients having palpable thyroid nodule. In this study, the total number of female patients were 122 and 48 patients were males.

All patients presented with swellings in front of neck $(100 \%)$ and majority presented between 6 months to 3 years. Other presenting complaints are pain, dysphagia, dyspnoea. Irfan Khan et al (2014). ${ }^{11}$ in their prospective study found that $96.40 \%$ of patients presented to them as palpable thyroid swellings. In a study conducted by Naveen et al in 2013 found all the patients presented to them as palpable thyroid swellings. 
Chetan V R et al (2013). ${ }^{12}$ in their study on thyroid on 100 patients found all patients presented with thyroid swelling. Numerous studies cited the following data. In our study, majority of thyroid swellings are solitary nodules (58\%) followed by MNG (22\%) and diffuse thyroid swellings in $20 \%$. Subhabharta et al (2014) in their study also found predominance of solitary nodule thyroid (35\%) over MND (33\%) and diffuse thyroid swellings (31\%). However, Kusum Kapila et al in their observation had preponderance of diffuse goitre $55.80 \%$, MNG and solitary nodule account for $18.30 \%$ and $29.90 \%$ respectively.

The euthyroid patients based on thyroid hormones analysis in our study was $50 \%$, whereas hypothyroid and hyperthyroid was $38 \%$ and $12 \%$. In the study of Fenn et al and Kusum Kapila et al, the euthyroid patients amounted for $46.66 \%$ and $79.30 \%$; the hypothyroid patients for $44.44 \%$ and $10.10 \%$ and hyperthyroid patients for $6.66 \%$ and $6.90 \%$ respectively. Sirish Chandanwalw et al, (78\%) patients were euthyroid, $18(12 \%)$ patients had hyperthyroidism and 15 $(10 \%)$ patients had hypothyroidism. In our study $28.94 \%$ patients have sub-clinical hypothyroidism, whereas in study of Marhawa et $\mathrm{al}^{13}$ have $18.60 \%$ of patients having subclinical hypothyroidism.

\section{CONCLUSION}

Total 100 cases of thyroid swellings were evaluated in Dr. Sushila Tiwari Government Hospital and Medical College, Haldwani, Uttarakhand, from November 2013 to November 2015 with respect to age, sex and duration of symptoms.

- Thyroid swellings is more common in females (M:F ratio 1:5.66).

- $\quad$ Majority of the patients are in the age group of 31-40 years.

- Swelling in the anterior neck was the commonest mode of presentation.

- In majority of the patients, duration of swelling prior to presentation was between 6 months and 3 years.

- The incidence of malignancy in solitary nodule of thyroid was $10 \%$.

- Most common presentation is solitary nodule $58 \%$ followed by multinodular goitre $22 \%$ and diffuse goitre $20 \%$.

- $\quad$ Out of 100 patients 38 are hypothyroid, 12 patients are hyperthyroid and 50 patients are euthyroid at the time of presentation.
- $\quad$ All patients in study presented with palpable thyroid swellings (Solitary, MNG, diffuse swelling); 15 patients presented with mild, diffuse, non-radiating pain around swellings; 12 patients have difficulty in swelling whereas 5 patients presented with difficulty in breathing on strenuous work.

- $\quad$ Lymph nodes were palpable in 8 patients out of 100 who presented with thyroid swelling.

\section{REFERENCES}

1. Leeta L, Orlo HC. Thyroid, parathyroid, and adrenal. In: Bruicardi FC, editor. Schwartz's principles of surgery. New York: Mcgraw Hill; 2005;8 th ed:1395-97.

2. Baskin JH. Thyroid ultrasound- just do it. Thyroid 2004;14(2):91-2.

3. Wong KT, Ahuja AT. Ultrasound of thyroid cancer. Cancer Imaging 2005;5(1):157-66.

4. Inderbir Singh B, Pal JP. Embryology of thyroid gland. Text book of Embroyology 2000;30-40.

5. Decker GA, Pleiss DJ. The thyroid, thymus and the parathyroid gland. Lee Mc gregors synopsis of surgical anatomy $1996 ; 12^{\text {th }}$ ed:198-205.

6. Miller FR, Netterville JL. Surgical management of thyroid and parathyroid disorders. Med Clin North Am 1999;83(1):247-59.

7. Jose RM, Smile SR, Lyengar KR. The role of imprint cytology in intraoperative diagnosis of thyroid swelling. Indian J Pathol Microbiol 2002;45(4):393-6.

8. Tabaqchali MA, Hanson JM, Johnson SJ, et al. Thyroid aspiration cytology in newcastle: a six year cytology histology correlation study. Ann R Coll Surg Engl 2000;82(3):149-55.

9. Sekhri T, Sankar JK, Bansal M, et al. Role of different diagnostic modalities in the evaluation of solitary thyroid nodule: experience in a tertiary referral centre of North India. IJNM 2001;16(3):105-8.

10. Afroze N, Kayam N, Hasan SH. Role of fine needle aspiration cytology in the diagnosis of palpable thyroid lesions. Indian J Pathol Microbiol 2002;45(3):241-6.

11. Irfan Khan, Mohsin UL Rasool, Imran khan, et al. A clinical study to see the relationship between thyroid swellings and various demographic factors in Northern India. Sch J App Med Sci 2014;2(4D):1441-4.

12. Sciences Chetan VR. International journal of research in medical. Int J Res Med Sci 2013;1(4):429-34.

13. Marwaha RK, Garg MK, Nijhavan VS, et al. Prevalence of chronic lymphocytic thyroiditis in adolescent girls. Journal of Association of Physicians of India 1998;46(7):606-8. 